Research Paper

\title{
Suppression of E-cadherin Mediates Gallotannin Induced Apoptosis in Hep G2 Hepatocelluar Carcinoma Cells
}

Hee Jeong Han ${ }^{2 *}$, Hee Young Kwon ${ }^{1 *}$, Eun Jung Sohn ${ }^{1^{*}}$, Hyunsuk Ko1, Bogeun Kim², Kwon Jung1, Jae Hwan Lew $^{2}$, Sung-Hoon Kim ${ }^{1}$

1. College of Korean Medicine, Kyung Hee University, 1 Hoegi-dong, Dongdaemun-gu, Seoul 131-701, Republic of Korea;

2. Graduate School of East-West Medical Science, Kyung Hee University, Yongin 449-701, Republic of Korea.

${ }^{*}$ Equally contributed authors.

$\triangle$ Corresponding author: Sung-Hoon Kim, O.M.D., Ph.D., Cancer Preventive Material Development Research Center, College of Oriental Medicine, Kyung Hee University, 1 Hoegi-dong, Dongdaemun-gu, Seoul 131-701, South Korea. Tel: 82-2-961-9233; Fax: 82-2-964-1064; E-mail: sungkim7@khu.ac.kr.

(c) Ivyspring International Publisher. This is an open-access article distributed under the terms of the Creative Commons License (http://creativecommons.org/ licenses/by-nc-nd/3.0/). Reproduction is permitted for personal, noncommercial use, provided that the article is in whole, unmodified, and properly cited.

Received: 2013.08.26; Accepted: 2014.01.09; Published: 2014.04.25

\begin{abstract}
Though gallotannin was known to have anti-oxidant and antitumor activity, the underlying antitumor mechanism of gallotannin still remains unclear. Thus, in the present study, antitumor mechanism of gallotannin was elucidated in hepatocellular carcinoma cells. Gallotannin significantly exerted cytotoxicity against Hep G2 and Chang hepatocellular carcinoma cells with the accumulation of the sub-GI population and increase of terminal deoxynucleotidyltransferasedUTP nick end labeling (TUNEL) positive cells as an apoptotic feature. Also, gallotannin attenuated the expression of pro-caspase9, pro-caspase3, Bcl2 and integrin $\beta I$ and cleaved poly(ADP)-ribose polymerase (PARP) in Hep $\mathrm{G} 2$ and Chang cancer cells. Furthermore, gallotannin suppressed cell repair motility by wound healing assay and also inhibited cell adhesion in Hep G2 cells. Of note, gallotannin attenuated the expression of epithelial cadherin (E-cadherin) to form cell-cell adhesion from the early stage, and also beta-catenin at late phase in Hep G2 cells. Consistently, Immunofluorescence assay showed that E-cadherin or $\beta$-catenin expression was suppressed in a time dependent manner by gallotannin. Furthermore, silencing of E-cadherin by siRNA transfection method enhanced PAPR cleavage, caspase 3 activation and sub GI population and attenuated the cell adhesion induced by gallotannin in Hep G2 cells. Overall, our findings demonstrate that the disruption of cell adhesion junction by suppression of E-cadherin mediates gallotannin enhanced apoptosis in Hep G2 liver cancer cells.
\end{abstract}

Key words: gallotannin, Hep G2 cells, apoptosis, PARP, caspase, E-cadherin.

\section{INTRODUCTION}

Hepatocellular carcinoma (HCC) as the fifth most common primary malignancy is worldwide increasing incidence $(1,2)$. Though several anti-cancer drugs have been treated to the HCC patients, it still resulted in side effects such as recurrence and multidrug resistance (3). Recent studies suggest that the potentials of natural products or herbal medicines such as curcumin, resveratrol showed the anti-cancer activities to the HCC (4-8). Furthermore, some herbal composite formula such as Shi-Quan-Bu-Tang, or
Xiao-Chai-Hu Tang were administrated to HCC patients $(9,10)$.

Gallotannin, polyphenolic hydrolysable tannin found in green tea has shown in multiple biological roles in anti- inflammatory (11), anti-oxidative (12), and anti-bacterial functions (13). In addition, previous studies showed that gallotannin prevented nephrolithiasis via suppression of calcium oxalate crystal binding and oxalate induced oxidative stress in renal epithelial cells (14). Though gallatonnin showed the 
proapoptotic actions in colon cancer cells (15) and lung cancer cells A549 (16), underlying anti-cancer mechanism of gallotannin in hepatocellular carcinoma still remains unknown.

E-cadherin which is located at the basolateral membrane in adherens junctions is a main marker of epithelial cell layers (17). Dysfunction of the adherens junction molecules such as E-cadherin and $\beta$-catenin play an important role in process of epithelial mesenchymal transition in development and tumorigenesis $(17,18)$. Mutation of E-cadherein was observed in highly invasive tumor cells line (19). Thus, in the current study, we for the first time investigated that gallotannin induced apoptosis via suppression of E-cadherin inhibiting invasive effects in Hep G2 hepatocellular carcinoma cells.

\section{MATERIALS AND METHODS}

\section{Reagents and Chemicals}

Gallotannin (Figure 1A) was purchased from Sigma-Aldrich (Sigma-Aldrich, St.Louis, MO, U.S.A.).

\section{Cell Culture}

Human liver cancer cell lines, Chang and Hep G2 cells were obtained from American Type Culture Collection (ATCC). The cells were cultured in RPMI 1640 (Welgene, Daegu, Korea) supplemented with $10 \%$ fetal bovine serum (FBS) (Welgene, Daegu, Korea) and $1 \%$ antibiotics at $37^{\circ} \mathrm{C}$ in a humidified $5 \%$ $\mathrm{CO}_{2}$ atmosphere.

\section{Cytotoxicity Assay Hep}

G2 or Chang cells at a density of $1 \times 10^{4}$ cells per well were incubated in the absence or presence of various concentrations of gallotannin for $48 \mathrm{~h}$. For cell viability study, XTT (2,3-Bis-(2-Methoxy-4-Nitro5-Sulfophenyl)-2H-Tetrazolium-5-Carboxanilide) (Sigma, USA) colorimetric assay was performed using XTT working solution prepared by mixing $1 \mathrm{~mL}$ of XTT stock solution $(1 \mathrm{mg} / \mathrm{mL}$ in phosphate buffered saline (PBS)) with $10 \mu \mathrm{L}$ of PMS (1.53 mg/mL in PBS). After $48 \mathrm{~h}$ treatment of gallotannin, a $50 \mu \mathrm{L}$ of XTT working solution was added to each well and incubated at $37^{\circ} \mathrm{C}$ for $2 \mathrm{~h}$. Then Microplate Reader (Sunrise, TECAN, Mannedorf, Switzerland) at $450 \mathrm{~nm}$ wavelength was used to measure the optical density (OD).

\section{Cell Cycle Analysis}

To measure DNA content, Hep G2 or Chang cells in absence or presence of gallotannin for $48 \mathrm{~h}$ were fixed in $75 \%$ ethanol at $-20^{\circ} \mathrm{C}$. The Fixed cells were washed twice with PBS and resuspended in PBS containing RNase A $(1 \mathrm{mg} / \mathrm{mL})$. After $1 \mathrm{~h}$ incubation at $37^{\circ} \mathrm{C}$, and the cells were stained with $400 \mu \mathrm{L}$ of Pro- pidium Iodide (PI) solution (50 $\mu \mathrm{g} / \mathrm{mL}$ stock) at room temperature for $30 \mathrm{~min}$ in the dark. Stained cells were analyzed by flow cytometry using FACSCalibur flow cytometer (Becton Dickinson, FranklinLakes, NJ, U.S.A.).

\section{Terminal deoxynucleotidyltransferasedUTP nick end labeling (TUNEL) assay}

DNA fragmentation in Hep G2 cells exposed to gallotannin for $48 \mathrm{~h}$ was analyzed by using Dead EndTM fluorometric TUNEL assay kit (Promega, Madison, WI, USA). The tissues were fixed in $4 \%$ methanol-free formaldehyde solution in PBS for 35 minutes at $4^{\circ} \mathrm{C}$ and treated with terminal deoxyribonucleotidyltransferase (TdT) enzyme buffer containing fluorescein-12-dUTP for 1 hour at $37{ }^{\circ} \mathrm{C}$ in the dark. The slides were mounted with mounting medium containing PI (Propidium Iodide) (VECTOR, Burlingame, CA, USA) and visualized under an Axio vision 4.0 fluorescence microscope (Carl Zeiss Inc., Weimar, Germany).

\section{Western Blotting}

Total cell lysates from Hep G2 or Chang cells in the presence of gallotannin for $48 \mathrm{~h}$ were extracted using lysis buffer (50 mM Tris- $\mathrm{HCl}, \mathrm{pH}$ 7.4, $150 \mathrm{mM}$ $\mathrm{NaCl}, 1 \%$ Triton X-100, $0.1 \%$ sodium dodecyl sulfate (SDS), $1 \mathrm{mM}$ ethylenediamineteraacetic acid (EDTA), $1 \mathrm{mM} \mathrm{Na} 3 \mathrm{VO} 4,1 \mathrm{mM} \mathrm{NaF}$, protease inhibitor cocktail). The proteins were separated on $4-12 \%$ Bis-Tris gels and electro-transferred onto a Hybond ECL transfer Membrane (GE Healthcare Bio-Science, Piscataway, NJ, U.S.A.). The membranes were blocked with 5\% nonfat dry milk and immunoblotted with antibodies such as pro-caspase-3, PARP, pro-caspase-9, Bcl-2, E-cadherin, beta catenin, integrin $\beta 1$ and beta actin (Cell signaling). Horseradish peroxidase-conjugated secondary anti-mouse or rabbit antibodies (AbD serotec, Kidlington, UK) were incubated. The protein expression was visualized by enhanced chemiluminescence (ECL) systems (Amersham Pharmacia, Piscataway, NJ).

\section{Wound-Healing Assay}

To measure the migratory ability of Hep G2 cells, a wound-healing assay was carried out. The confluent cells in the absence or presence of gallotannin were scratched with a $200 \mu \mathrm{L}$ pipet tip, followed by washing with PBS. One day later, Hep G2 cells were fixed and stained with Diff-Quick, and photographed under a fluorescence microscope (AXIO observer A1, Zeiss, Germany). The number of migrated cells into the scratched area was counted.

\section{Adhesion Assay}

Hep G2 cells at $5 \times 10^{4}$ cells per well 
pre-incubated in the presence of gallotannin $(4 \mu \mathrm{M})$ for $20 \mathrm{~min}$ at $37^{\circ} \mathrm{C}$ were seeded in a Matrigel coated plate for $10 \mathrm{~min}$ at $37^{\circ} \mathrm{C}$. After washing with PBS to remove unattached cells, attached cells were fixed in 1\% glutaraldehyde in PBS for $20 \mathrm{~min}$ followed by staining with $0.02 \%$ crystal violet solution for $5 \mathrm{~min}$ at room temperature. Randomly chosen fields were photographed under a fluorescence microscope (AXIO observer A1, Zeiss). The attached cells were calculated for cell-cell adhesion percentage.

\section{siRNA transfection assay}

Small interfering RNA (siRNAs) for E-cadherin (Bioneer, Daejun, South Korea) or control vector (80 $n M)$ was transfected using INTERFERin ${ }^{\circledR}$ reagent (Polyplus, IIIkirch, France) in Hep G2 cells. One day after transfection, gallotannin $(4 \mu \mathrm{M})$ was treated in Hep G2 cells for $48 \mathrm{~h}$.

A

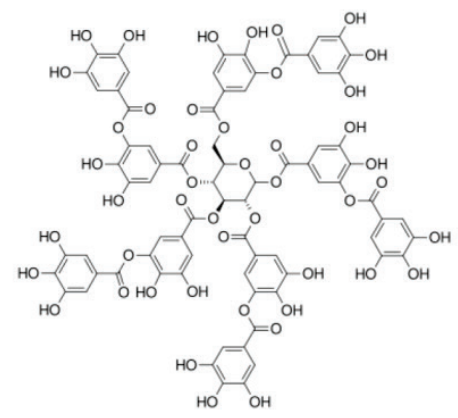

Gallotannin

\section{C}
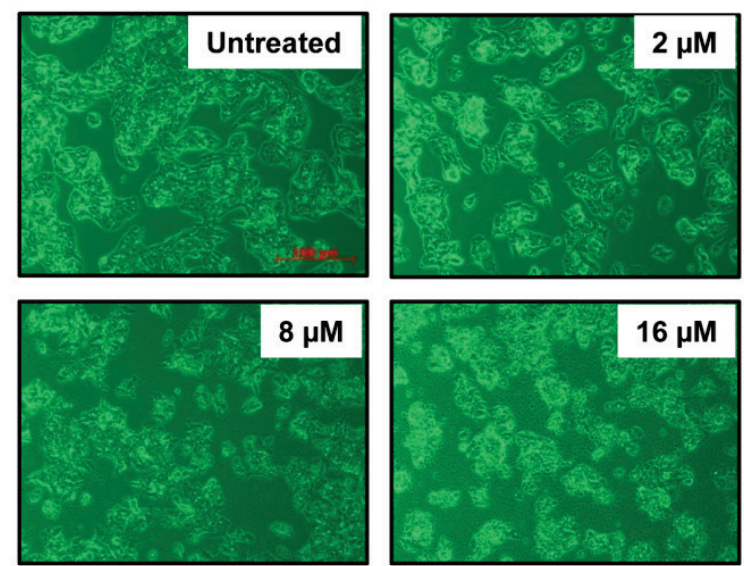

D
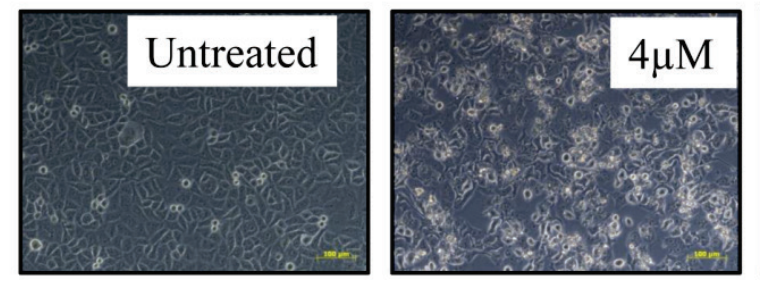

B
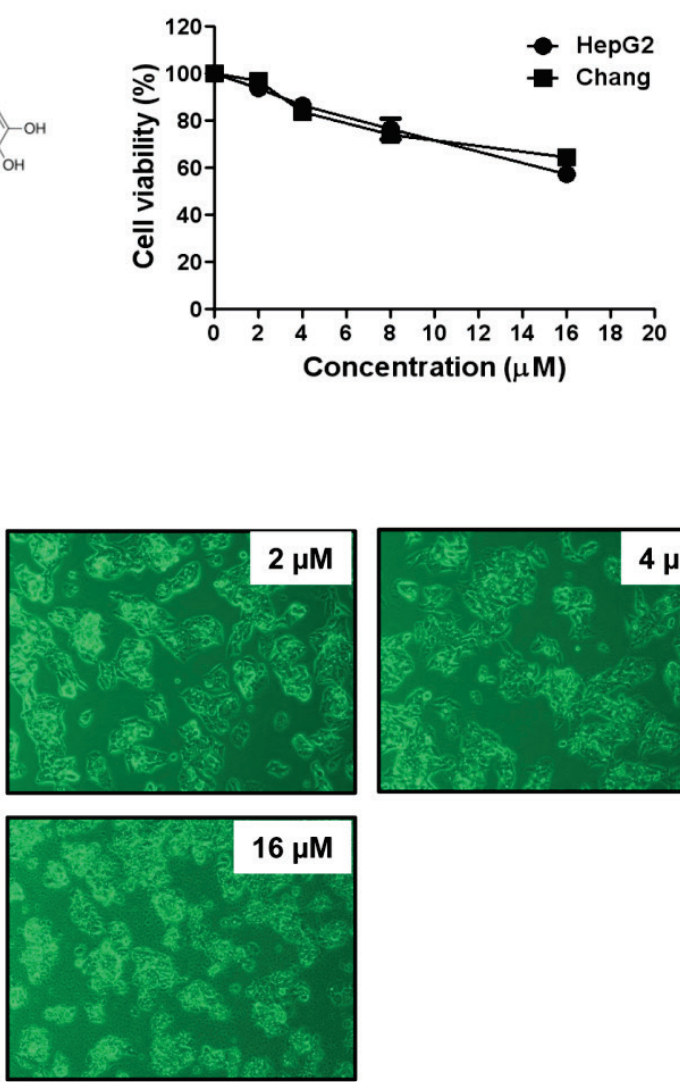

\section{Statistical Analyses}

To statistical analysis of the data, Sigmaplot version 12 software (Systat Software Inc., San Jose, CA, U.S.A.) was used. All data were presented as means \pm standard deviation (S.D.). Statistical significance between control and gallotannin-treated groups was analyzed using the Student's $t$-test.

\section{RESULTS}

\section{Gallotannin exerted cytotoxicity against Hep G2 and Chang hepatocellular carcinoma cells.}

Cytotoxicity of gallotannin in human liver cancer cell lines, Hep G2 and Chang cells was evaluated by XTT assay. After various concentrations $(0,2,4,8,16$ $\mu \mathrm{M})$ of gallotannin were treated in Hep G2 and Chang cells for $48 \mathrm{~h}$, cell viability was determined. As shown in Figure 1 B, gallotannin showed significant cytotoxicity in Hep G2 and Chang cells after $48 \mathrm{~h}$ culture. We also confirmed the apoptotic bodies like cell shrinkage in gallotannin treated Hep G2 and Chang cells under an inverted microscope (Figure 1C and D).

Figure I. Gallotannin exerted the cytotoxicity against Hep $\mathrm{G} 2$ and Chang hepatocellular carcinoma cells. (A) Structure of gallotannin. (B) Cytotoxicity of gallotannin in Hep G2. Hep G2 cells were treated with various concentrations of gallotannin $(0,2$, 4,8 , or $16 \mu \mathrm{M}$ ) for $48 \mathrm{~h}$ and XTT assay was used.to find out cytotoxicity and apoptotic morphological changes in gallotannin treated Hep G2 (C) or Chang (D) cells under inverted microscopy at $\times 200$ magnification.

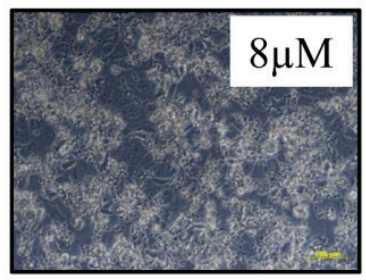




\section{Gallotannin increased sub G-I population in Hep G2 and Chang cells.}

In order to confirm whether the cytotoxicity of gallotannin in Hep G2 or Chang cells was due to apoptosis induction, cell cycle analysis using flow cytometry with PI staining was performed. As shown in Figure $2 \mathrm{~A}$ and B, gallotannin significantly increased the accumulation of sub-G1 apoptotic portion in a dose-dependent manner in Hep G2 and Chang cells compared to untreated control. Consistently, Western blotting revealed that gallotannin cleaved PARP and attenuated the expression of pro-caspase 9/3, Bcl 2 and integrin $\beta 1$ in a dose dependent manner in Hep G2 or Chang cells (Figure 2C). Also, we confirmed that gallotannin induced apoptosis in Hep G2 or Chang cells by TUNEL assay (Figure 2D).

A

\section{HepG2- 48 h}
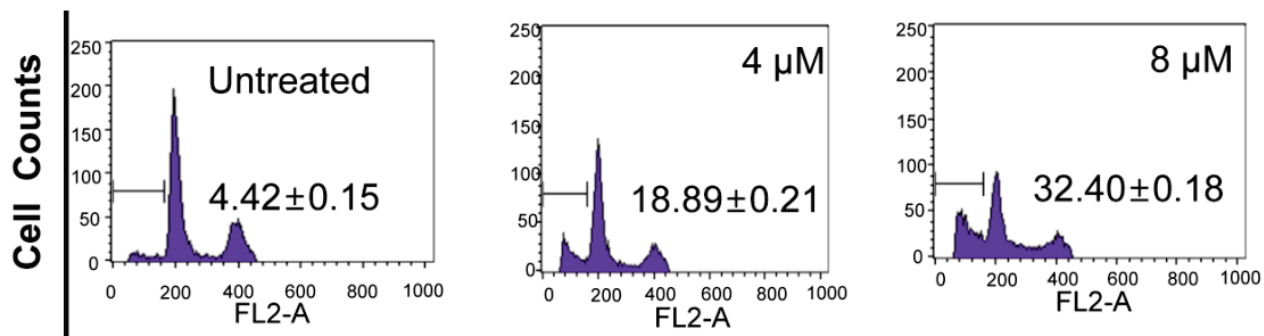

Fluorescence intensity

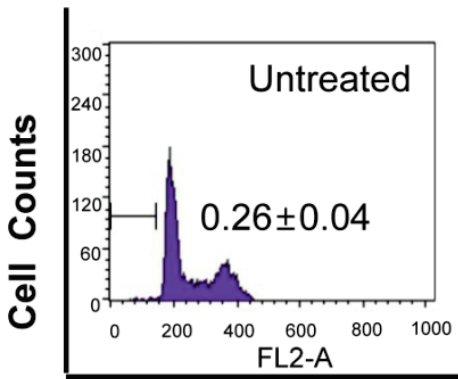

\section{Chang - $48 \mathrm{~h}$}
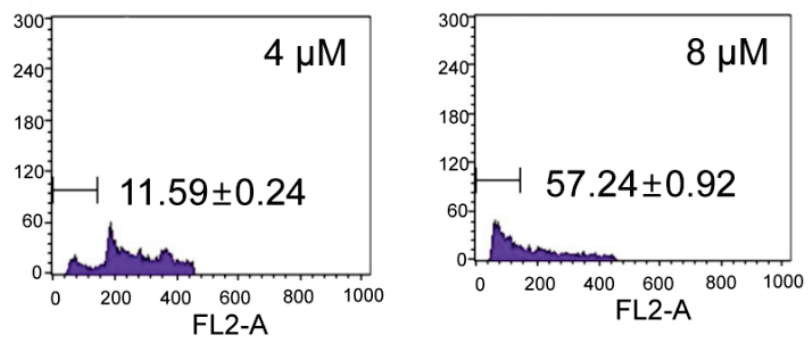

B

\section{Fluorescence intensity}
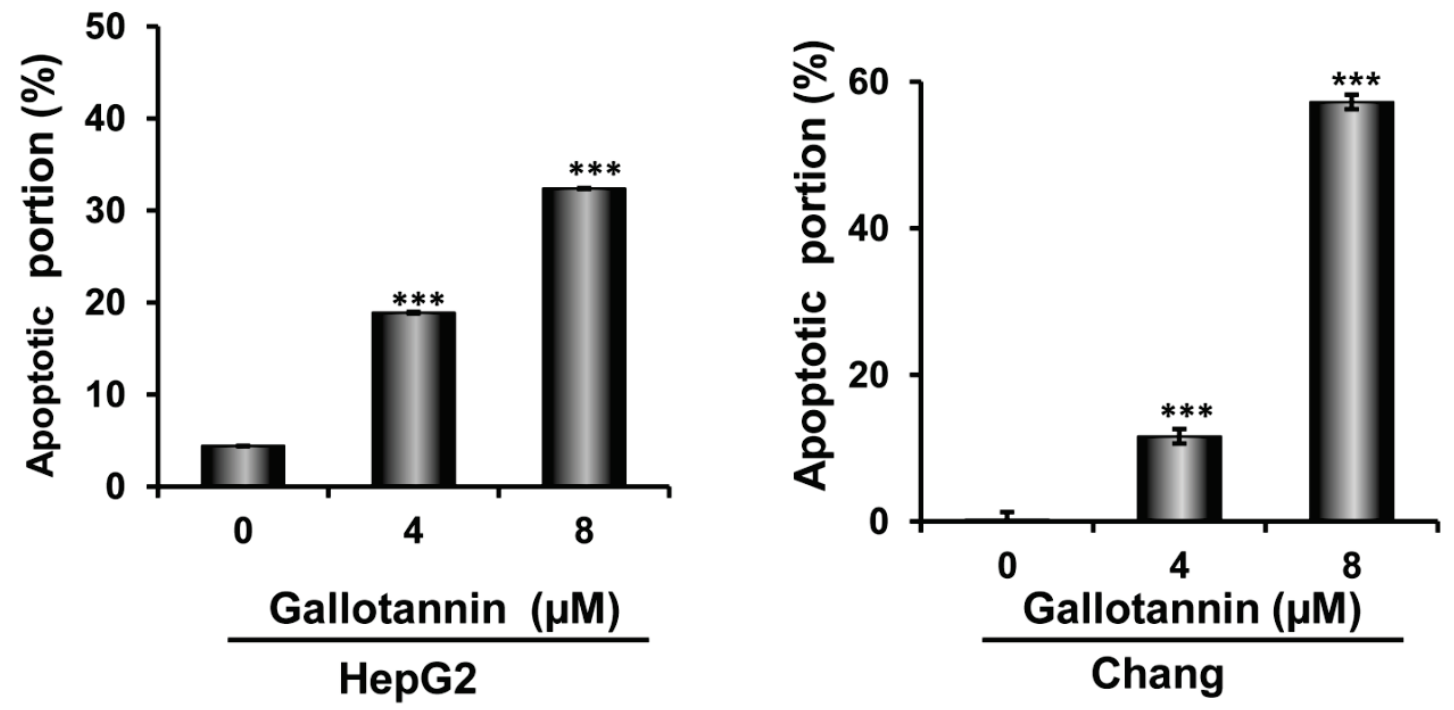
C
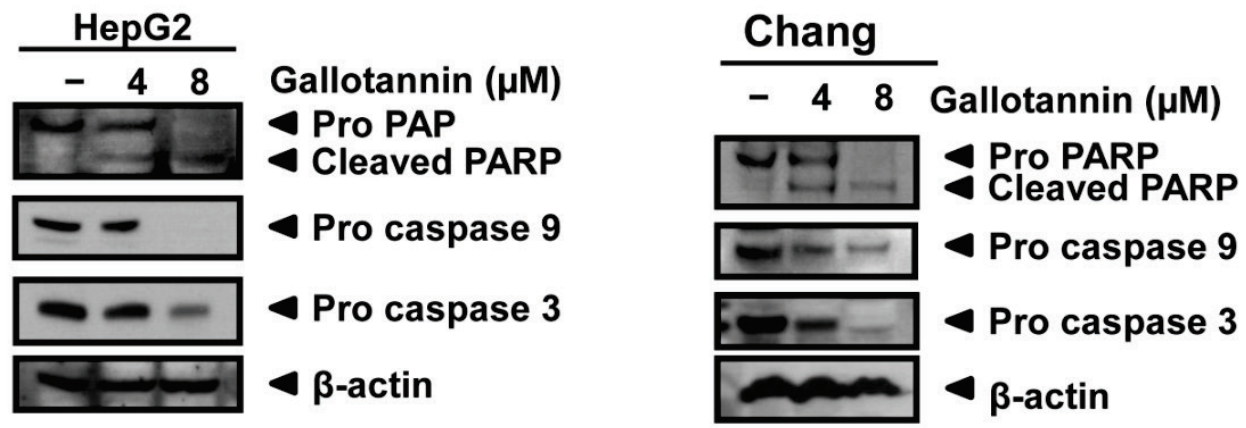

D

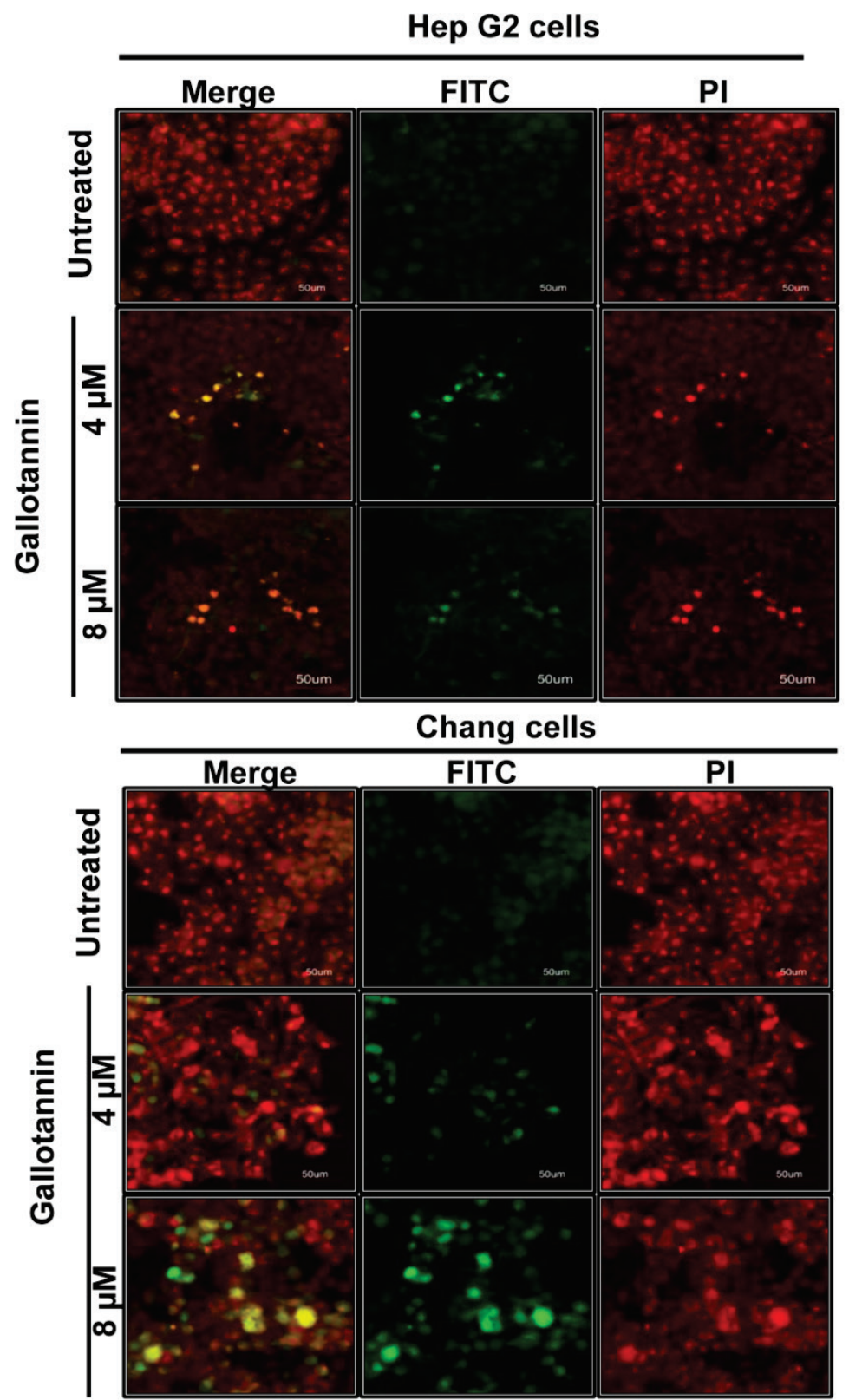

Figure 2. Gallotannin increased sub-GI population and regulated apoptotic genes in Hep G2 and Chang cells. (A) Effect of gallotannin on sub GI population by FACS analysis with propidium iodide (PI) staining. Hep G2 and Chang cells were treated with various concentrations of gallotannin (0, 4, $8 \mu \mathrm{M})$ for $48 \mathrm{~h}$ and stained with $\mathrm{PI}$ using Flow cytometry. (B) Bar graphs for sub-GI population in Hep G2 and Chang cells. ***, $p<0.00$ I, vs untreated control. (C) Effect of gallotannin on apoptotic proteins in Hep G2 and Chang cells. Cell lysates from gallatonnin treated Hep G2 and Chang cells were subjected for western blotting for PARP, pro-caspase 9 and 3 , Bcl2 and $\beta$-Actin. (D) Apoptotic cells were detected by TUNEL assay. Cells in the absence or presence of gallotannin were stained with TUNEL-FITC (Green) and PI (Red). Data represent means \pm S.D. 


\section{Gallotannin suppressed the migratory and adhesive ability of Hep $\mathbf{G} 2$ cells.}

In order to check the migratory and adhesive ability of gallotannin in Hep G2 cells, wound healing and adhesion assay were carried out. As shown in Figure 3A, gallotannin at $4 \mu \mathrm{M}$ significantly decreased the migration of Hep G2 cells compared to untreated

A

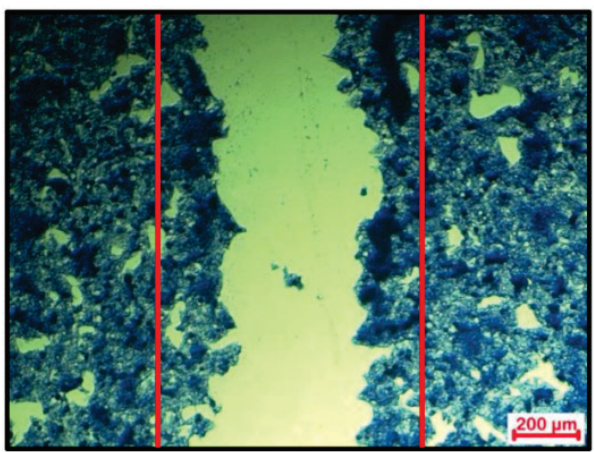

Untreated

B
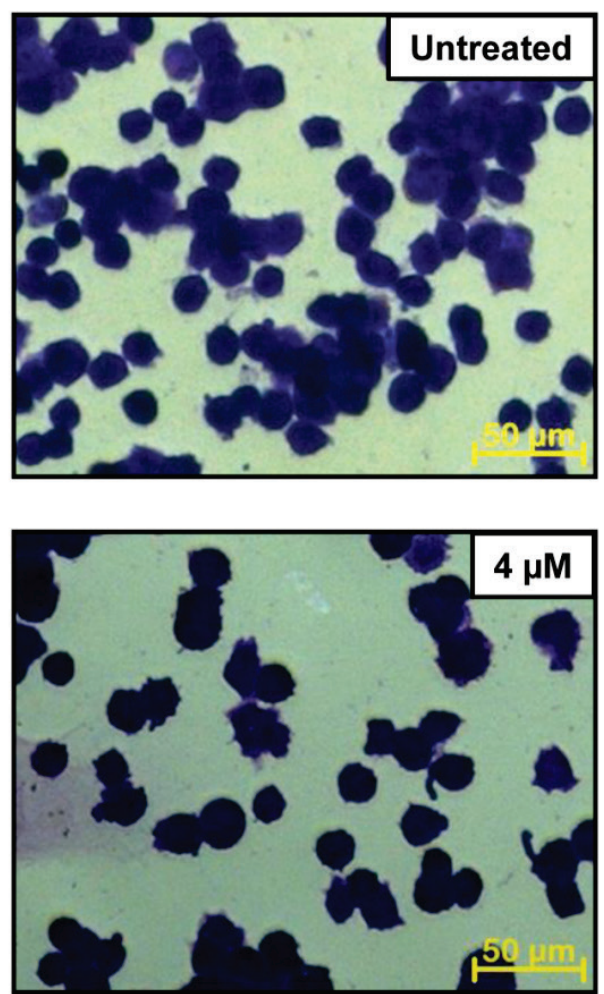

control. Furthermore, treatment of gallotannin $(4 \mu \mathrm{M})$ resulted in significant reduction of cell adhesion to Matrigel coated plate compared to untreated control (Figure $3 \mathrm{~B}, \mathrm{C}$ ). Integrin $\beta 1$ which is well characterized as a cell adhesion receptor was downregulated in gallotannin treated Hep G2 cells (Figure 3D).

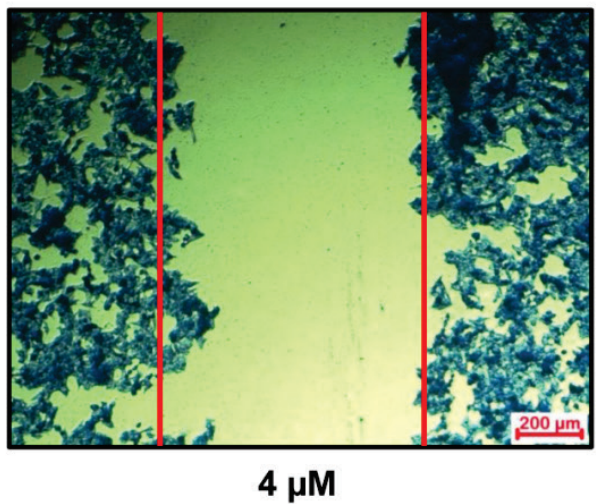

C

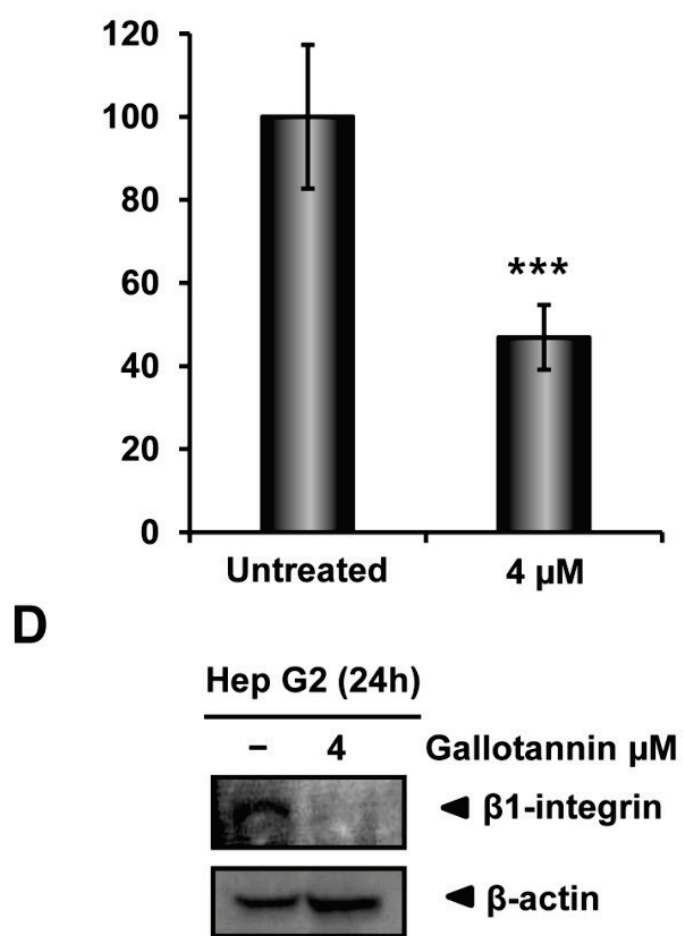

Figure 3. Gallotannin suppressed the migration and adhesion of Hep G2 cells. (A) Effect of gallotannin on the migration of Hep G2 cells by wound healing assay. Confluent cells were scratched and then treated with gallotannin in a complete medium for $24 \mathrm{~h}$. The number of cells migrated into the scratched area was photographed $(\times 100)$. (B) Effect of gallotannin on the adhesion to Matrigel coated plate after 20 min exposure. Attached cells were photographed $(\times 200)$ after crystal violet staining $(C)$ Quantification of attached cells. Scale bar $=100 \mu \mathrm{m}$. ***, $p<0.00 \mathrm{I}$, vs untreated control. (D) Western blotting was performed with antibody of integrin $\beta \mathrm{I}$ in Hep G2 cells exposed to gallotannin for $24 \mathrm{~h}$ 


\section{Gallotannin attenuated the expression of E-cadherin and beta catenin in Hep $\mathbf{G} 2$ cells.}

There are evidences for the role of E-cadherin in apoptosis in cancer cells (20-23). In this regards, we examined the role of E-cadherin in gallotannin induced apoptosis in Hep G2 cells. As shown in Figure 4 A, gallotannin attenuated the expression of E-cadherin in a time dependent manner from $24 \mathrm{~h}$ after treatment, while the expression of beta catenin was effectively reduced in Hep G2 cells only at $72 \mathrm{~h}$ after treatment (Figure 4 A, B). We also confirmed that red color expression for E-cadherin around cell membrane or $\beta$-catenin was effectively attenuated in gallotannin treated Hep G2 cells compared to untreated control by immunofluorescence assay (Figure $4 \mathrm{C}$ or D).

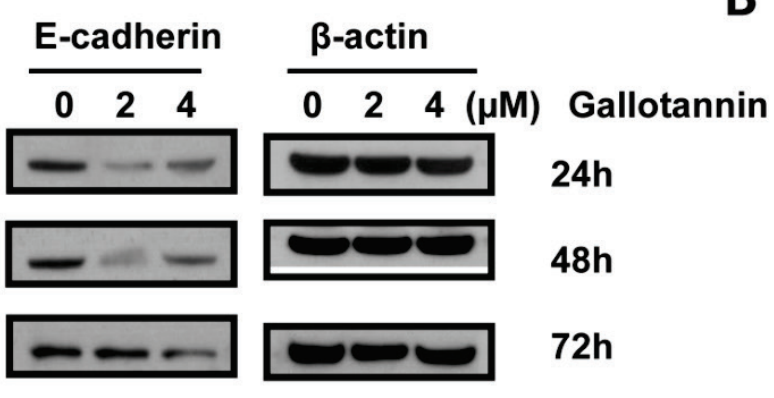

A
B

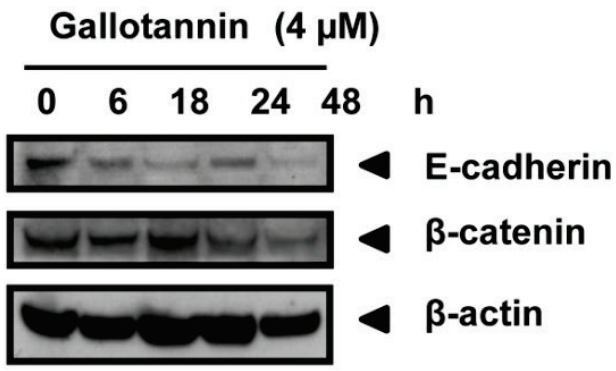

C

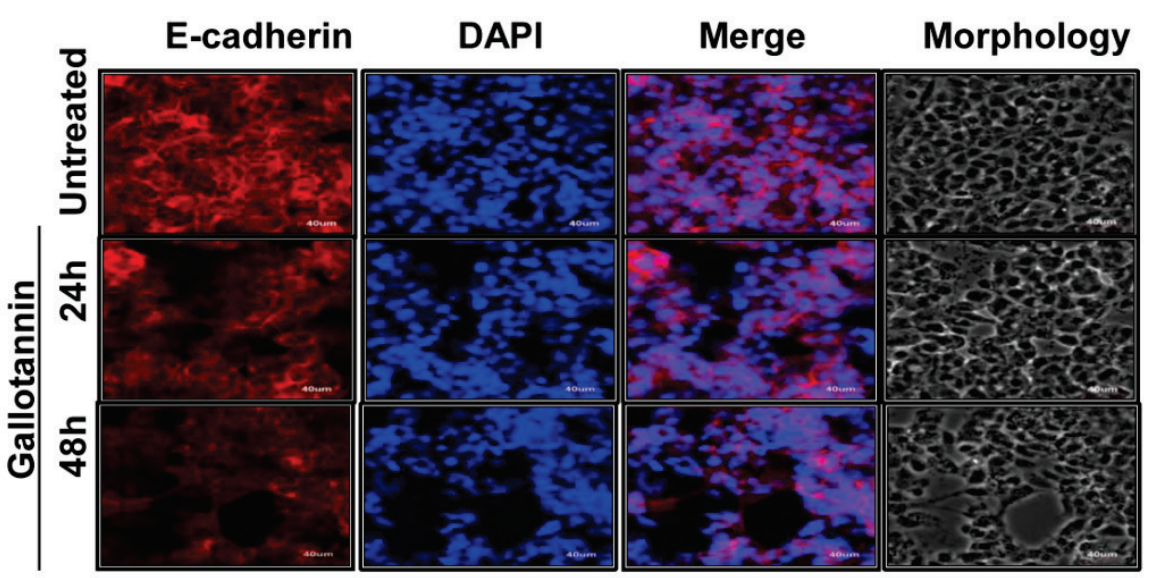

D

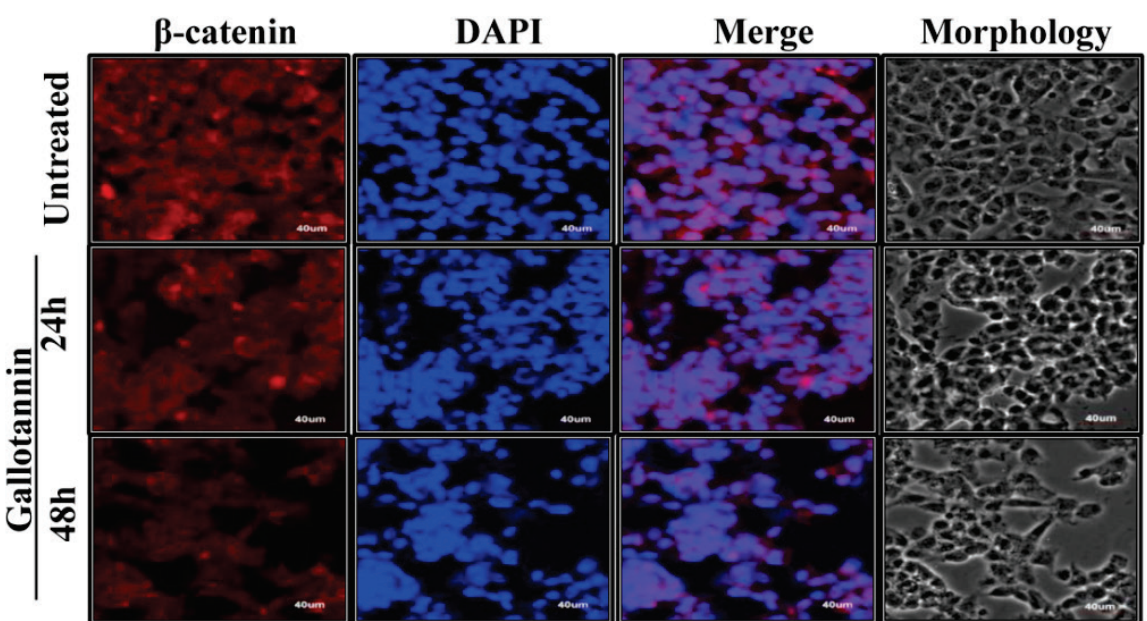

Figure 4. Gallotannin attenuated the expression of E-cadherin, and beta-catenin in Hep G2 cells. (A) Effect of gallotannin on E-cadherin in Hep G2 cells in a concentration $(0,2,4 \mu \mathrm{M})$ and time dependent manner $(24,48$ or $72 \mathrm{~h})$ by Western blotting (B) Effect of gallotannin on E-cadherin and beta-catenin in Hep $\mathrm{G} 2$ cells in time courses $(0,6,18,24,48 \mathrm{~h}$ ) by Western blotting. Effect of gallotannin on E-cadherin (C) or $\beta$-catenin (D) localization in Hep G2 cells in Hep G2 cells by Immunofluorescence assay. Hep $\mathrm{G} 2$ cells in the absence or presence of gallotannin $(4 \mu \mathrm{M})$ were fixed and immunostained with $\alpha$-E-cadherin antibody. Nuclei were stained with DAPI. Scale bar, $40 \mu \mathrm{m}$. 


\section{Silencing of E-cadherin enhanced gallotannin induced apoptosis in Hep $\mathbf{G} 2$ cells.}

Next, we investigated whether E-cadherin mediates apoptosis in gallotannin treated Hep G2 cells by using siRNA transfection of E-cadherin. Twenty four hours after transfection with control or E-cadherin siRNA, gallotannin was treated in Hep G2 cells for $48 \mathrm{~h}$. As shown in Figure 5A, silencing of E-cadherin enhanced PARP cleavage and caspase 3

A

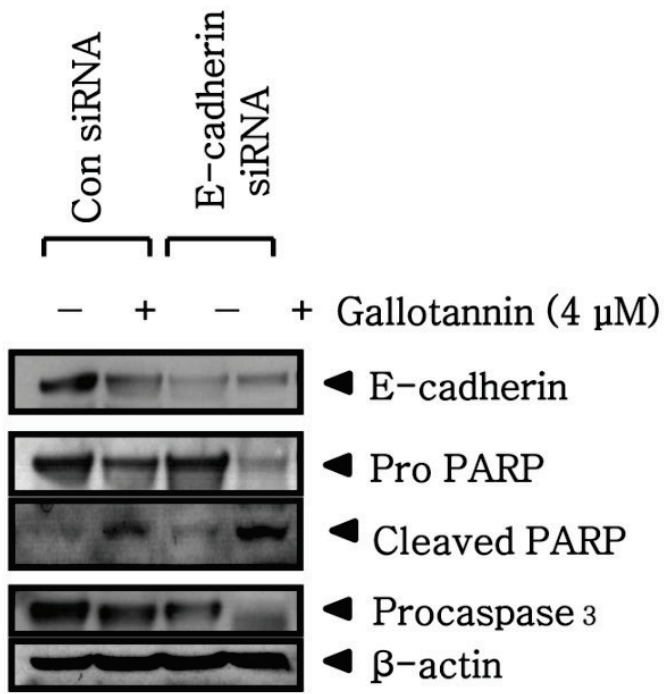

B
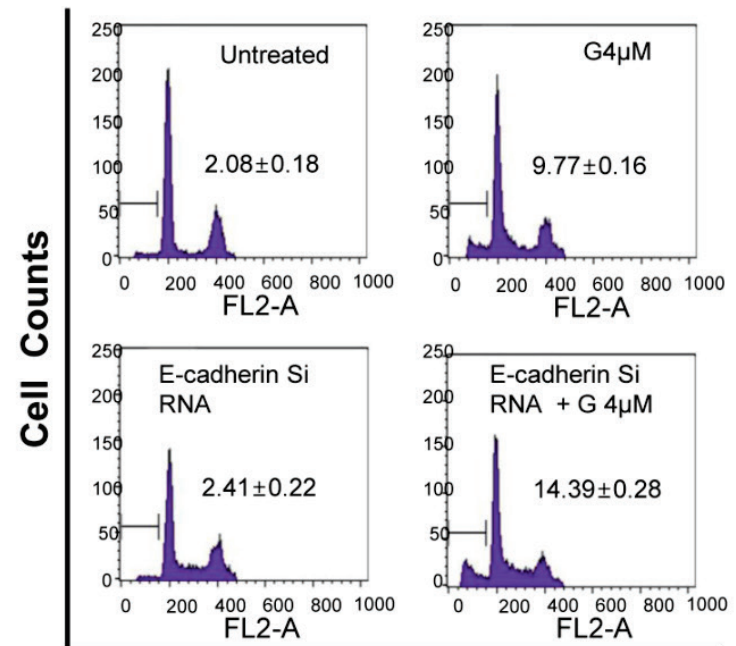

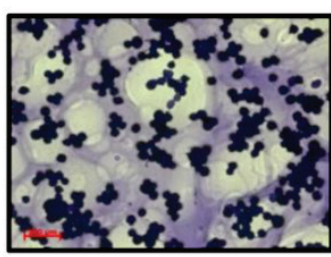

Con siRNA

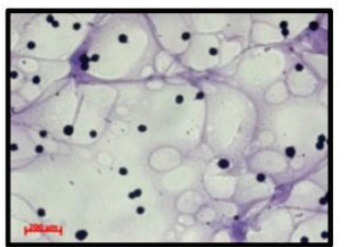

E-cadherin siRNA

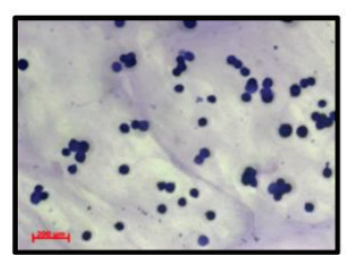

Gallotannin

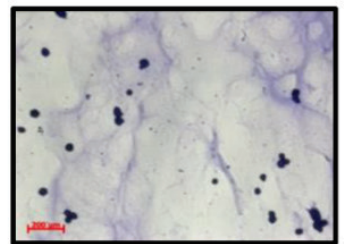

E-cadherin siRNA

+ Gallotannin

Fluorescence intensity

Figure 5. Silencing of E-cadherin enhanced apoptosis and sub $\mathbf{G I}$ population induced by gallotannin in Hep G2 cells. One day after transfection with control vector or E-cadherin siRNA plasmid, gallotannin $(4 \mu \mathrm{M})$ was treated in Hep G2 cells for $48 \mathrm{~h}$. (A) Effect of gallotannin on E-cadherin, PARP and pro-caspase 3 in Hep G2 cells transfected by control vector or E-cadherin siRNA plasmid. (B) Effect of gallotannin on sub GI population in Hep G2 cells transfected by control vector or E-cadherin siRNA plasmid by FACS analysis. Bar graphs showing the percentages of sub-GI DNA contents undergoing apoptosis. (C) Effect of gallotannin on the adhesion to Matrigel coated plate in Hep G2 cells transfected by control vector or E-cadherin siRNA plasmid $* * *, p<0.001$, vs untreated control. \#\#, $p<0.00$ I, vs gallotannin treated group. 


\section{DISCUSSION}

Polyphenolic compounds such as ellagitannins (24), and oligomeric proanthocyanidins (25) induced apoptosis and inhibited the growth of several human cancer cells. Furthermore, pentagalloyl glucose (PGG) which is the precursor of gallotannin has been shown to induce cell cycle arrest and apoptosis $(26,27)$, and suppress angiogenesis and tumor growth in vivo (28). Gallotannin, a water soluble polyphenol, was known to have antitumor activity in several cancers such in colon (15, 29), lung (16) and breast (30). Al-Ayyoubi et al reported that gallotannin inhibited the growth of HCT-116 colon cancer cells and also induced apoptosis in HCT-116 p53 (+/+) cells (15). Yu et al suggested that gallotannin induced apoptosis in A549 lung cancer cells via phosphorylation of Akt and p38 signaling and induction of COX-2(16). Nevertheless, the underlying antitumor mechanism of gallotannin was not fully understood until now. Thus, in the current study, antitumor mechanism of gallotannin was elucidated in Hep G2 and Chang hepatocellular carcinoma cells. Gallotannin showed significant cytotoxicity in Hep G2 and Chang cells and also significantly increased sub-G1 population, implying the cytotoxicity of gallotannin was exerted by apoptosis induction.

In general, apoptosis is induced via two distinct pathway such as the extrinsic death receptor pathway and intrinsic mitochondrial pathway $(31,32)$. Gallotannin attenuated the expression of procaspase9, pro-caspase $3, \mathrm{Bcl} 2$ and integrin $\beta 1$ and increased the cleavages of poly (ADP)-ribose polymerase (PARP) in Hep G2 carcinoma cells, indicating mitochondrial dependent apoptosis by gallotannin after $48 \mathrm{~h}$ exposure in Hep G2 hepatocellular carcinoma cells.

Cadherins, calcium dependent cell-cell adhesion molecules to coordinate morphogenetic cell movement, mainly consist of epithelial cadherin (E-cadherin), placental cadherin (P-cadherin) and neuronal cadherin (E-cadherin) $(33,34)$. Here, gallotannin attenuated the expression of E-cadherin to form cell-cell adhesion from the early stage, and also beta-catenin to form cell-cell adhesion complex with E-cadherin at late phase in Hep G2 cells, implying gallotannin can regulate cell-cell adhesion complex of E-cadherin and beta catenin.

There are evidences that cell adhesion involvement in tumorigenesis and invasion focused on E-cadherin, given that this molecule is the major cadherin involved in epithelial cell-cell adhesion, and the majority of cancers originate from epithelial cells $(35,36)$. Wound healing assay revealed gallotannin suppressed cell repair motility after $24 \mathrm{~h}$ expoure and also adhesion assay showed gallotannin inhibited cell adhesion to Matrigel coated plate at nontoxic concentrations only after 20 min exposure in Hep G2 cells, implying the inhibitory effect of gallotannin on migration and adhesion to extracellular matrix in epithelium. Consistently, Immunofluorescence assay confirmed that red color E-cadherin expression around membrane was reduced compared to untreated control in Hep G2 cells.

There are previous evidences that E-cadherin is involved in adhesion and apoptosis. Loss of cell to cell contact resulted in anoikis which is a specific apoptotic process (37) and loss of E-cadherin and beta catenin led to an early trigger of apoptosis $(22,23)$. Also, E-cadherin known as a substrate for caspase 3 (20), prevented the apoptosis in immmortalized granuloma cells (38) and suppressed the anoikis in Ewing sarcoma cells (21). Several studies suggest that degradation of E-cadherin and beta-catenin is processed by the lysosome and the proteasome upon junction disorganization (39) and caspases upon apoptosis $(40,41)$. Similarly, in the current study, silencing of E-cadherin representing loss of E-cadherin enhanced PARP cleavage and caspase 3 activation as well as the accumulation of sub G1 contents induced by gallotannin in Hep G2 cells, demonstrating the loss of E-cadherin initiates apoptosis induction at early stage in Hep G2 cells. Nonetheless, the exact molecular mechanism by which silencing of E-cadherin enhances gallatonnin induced apoptosis as an indirect initiator of apoptosis still remains unclear. Thus, further study is requested to elucidate the exact role of E-cadherin in apoptosis induction in vitro and in vivo in the future. Overall, our findings demonstrate that gallotannin enhanced apoptosis in Hep G2 hepatocellular cancer cells partly via the disruption of cell adhesion junction by suppression of E-cadherin as a potent chemopreventive agent for liver cancer treatment and prevention.

\section{Acknowledgements}

This work was supported by the National Research Foundation of Korea (NRF) grant funded by the Korea government (MSIP) (No. 2007-0054931).

\section{Competing Interests}

The authors have declared that no competing interest exists.

\section{References}

1. Baffy G, Brunt EM, Caldwell SH. Hepatocellular carcinoma in non-alcoholic fatty liver disease: an emerging menace. J Hepatol 2012;56(6):1384-91.

2. Jemal A, Siegel R, Ward E, Hao Y, Xu J, Murray T, et al. Cancer statistics, 2008. CA Cancer J Clin 2008:58(2):71-96.

3. Villanueva A, Llovet JM. Second-line therapies in hepatocellular carcinoma: emergence of resistance to sorafenib. Clin Cancer Res 2012;18(7):1824-6.

4. Sun Z, Liang ST, Zhai XF, Lang QB, Zhou QH, Yue XQ, et al. A traditional Chinese herbal medicine compound preparation versus interventional therapy 
after resection of small hepatocellular carcinoma: 22-year follow-up. J Tradit Chin Med 2012;32(2):156-63.

5. Li Y, Martin RCG. Herbal medicine and hepatocellular carcinoma: applications and challenges. Evid Based Complement Alternat Med; 2011;:541209.

6. Yu Y, Lang Q, Chen Z, Li B, Yu C, Zhu D, et al. The efficacy for unresectable hepatocellular carcinoma may be improved by transcatheter arterial chemoembolization in combination with a traditional Chinese herbal medicine formula: a retrospective study. Cancer 2009;115(22):5132-8.

7. Huang XY, Wang L, Huang ZL, Zheng Q, Li QS, Tang ZY. Herbal extract "Songyou Yin" inhibits tumor growth and prolongs survival in nude mice bearing human hepatocellular carcinoma xenograft with high metastatic potential. J Cancer Res Clin Oncol 2009;135(9):1245-55.

8. Li Y, Martin RC, 2nd. Herbal medicine and hepatocellular carcinoma: applications and challenges. Evid Based Complement Alternat Med 2011;2011:541209.

9. Tsuchiya M, Kono H, Matsuda M, Fujii H, Rusyn I. Protective effect of Juzen-taiho-to on hepatocarcinogenesis is mediated through the inhibition of Kupffer cell-induced oxidative stress. Int J Cancer 2008;123(11):2503-11.

10. Oka H, Yamamoto S, Kuroki T, Harihara S, Marumo T, Kim SR, et al. Prospective study of chemoprevention of hepatocellular carcinoma with Sho-saiko-to (TJ-9). Cancer 1995;76(5):743-9.

11. Erdelyi K, Kiss A, Bakondi E, Bai P, Szabo C, Gergely P, et al. Gallotannin inhibits the expression of chemokines and inflammatory cytokines in A549 cells. Mol Pharmacol 2005;68(3):895-904.

12. Zhao X, Sun H, Hou A, Zhao Q, Wei T, Xin W. Antioxidant properties of two gallotannins isolated from the leaves of Pistacia weinmannifolia. Biochim Biophys Acta 2005;1725(1):103-10.

13. Engels C, Knodler M, Zhao YY, Carle R, Ganzle MG, Schieber A. Antimicrobial activity of gallotannins isolated from mango ( Mangifera indica L.) kernels. J Agric Food Chem 2009;57(17):7712-8.

14. Lee HJ, Jeong SJ, Park MN, Linnes M, Han HJ, Kim JH, et al. Gallotannin suppresses calcium oxalate crystal binding and oxalate-induced oxidative stress in renal epithelial cells. Biol Pharm Bull 2012;35(4):539-44.

15. Al-Ayyoubi S, Gali-Muhtasib H. Differential apoptosis by gallotannin in human colon cancer cells with distinct p53 status. Mol Carcinog 2007;46(3):176-86.

16. Yu S-M, Gweon E-J, Chung K-W, Kim K-H, Cho H-S, Kim S-J. Gallotannin regulates apoptosis and COX-2 expression via Akt and p38kinase pathway in human lung cancer cell line, A549. Animal Cells and Systems 2012;16(5):366-375.

17. Schmalhofer O, Brabletz S, Brabletz T. E-cadherin, beta-catenin, and ZEB1 in malignant progression of cancer. Cancer Metastasis Rev 2009;28(1-2):151-66.

18. Brabletz T, Hlubek F, Spaderna S, Schmalhofer O, Hiendlmeyer E, Jung A, et al. Invasion and metastasis in colorectal cancer: epithelial-mesenchymal transition, mesenchymal-epithelial transition, stem cells and beta-catenin. Cells Tissues Organs 2005;179(1-2):56-65.

19. Nollet F, Berx G, van Roy F. The role of the E-cadherin/catenin adhesion complex in the development and progression of cancer. Mol Cell Biol Res Commun 1999;2(2):77-85

20. Schmeiser K, Grand RJ. The fate of E- and P-cadherin during the early stages of apoptosis. Cell Death Differ 1999;6(4):377-86

21. Kang HG, Jenabi JM, Zhang J, Keshelava N, Shimada H, May WA, et al. E-cadherin cell-cell adhesion in ewing tumor cells mediates suppression of anoikis through activation of the ErbB4 tyrosine kinase. Cancer Res 2007:67(7):3094-105.

22. Galaz S, Espada J, Stockert JC, Pacheco M, Sanz-Rodriguez F, Arranz R, et al. Loss of E-cadherin mediated cell-cell adhesion as an early trigger of apoptosis induced by photodynamic treatment. J Cell Physiol 2005;205(1):86-96.

23. Fouquet S, Lugo-Martinez VH, Faussat AM, Renaud F, Cardot P, Chambaz J, et al. Early loss of E-cadherin from cell-cell contacts is involved in the onset of Anoikis in enterocytes. J Biol Chem 2004;279(41):43061-9.

24. Chen LG, Huang WT, Lee LT, Wang CC. Ellagitannins from Terminalia calamansanai induced apoptosis in HL-60 cells. Toxicol In Vitro 2009;23(4):603-9.

25. Chung WG, Miranda CL, Stevens JF, Maier CS. Hop proanthocyanidins induce apoptosis, protein carbonylation, and cytoskeleton disorganization in human colorectal adenocarcinoma cells via reactive oxygen species. Food Chem Toxicol 2009;47(4):827-36.

26. Kwon TR, Jeong SJ, Lee HJ, Sohn EJ, Jung JH, Kim JH, et al. Reactive oxygen species-mediated activation of JNK and down-regulation of DAXX are critically involved in penta-O-galloyl-beta-d-glucose-induced apoptosis in chronic myeloid leukemia K562 cells. Biochem Biophys Res Commun 2012;424(3):530-7.

27. Hu H, Zhang J, Lee HJ, Kim SH, Lu J. Penta-O-galloyl-beta-D-glucose induces S- and G(1)-cell cycle arrests in prostate cancer cells targeting DNA replication and cyclin D1. Carcinogenesis 2009;30(5):818-23.

28. Huh JE, Lee EO, Kim MS, Kang KS, Kim CH, Cha BC, et al. Penta-O-galloyl-beta-D-glucose suppresses tumor growth via inhibition of angiogenesis and stimulation of apoptosis: roles of cyclooxygenase-2 and mitogen-activated protein kinase pathways. Carcinogenesis 2005;26(8):1436-45.

29. Al-Halabi R, Bou Chedid M, Abou Merhi R, El-Hajj H, Zahr H, Schneider-Stock R, et al. Gallotannin inhibits NFkB signaling and growth of human colon cancer xenografts. Cancer Biol Ther 2011;12(1):59-68.

30. Uruena C, Mancipe J, Hernandez J, Castaneda D, Pombo L, Gomez A, et al. Gallotannin-rich Caesalpinia spinosa fraction decreases the primary tumor and factors associated with poor prognosis in a murine breast cancer model. BMC Complement Altern Med 2013;13:74.

31. Ouyang L, Shi Z, Zhao S, Wang FT, Zhou TT, Liu B, et al. Programmed cell death pathways in cancer: a review of apoptosis, autophagy and programmed necrosis. Cell Prolif 2012;45(6):487-98.

32. Elmore S. Apoptosis: a review of programmed cell death. Toxicol Pathol 2007;35(4):495-516

33. Gama A, Schmitt F. Cadherin cell adhesion system in canine mammary cancer: a review. Vet Med Int;2012;2012:357187-95.

34. Yap AS. The morphogenetic role of cadherin cell adhesion molecules in human cancer: a thematic review. Cancer Invest 1998;16(4):252-61.

35. Raftopoulos I, Kouraklis G. Dysfunction of the E-cadherin/catenin cell adhesion cascade in epithelial cancers (Review). Oncol Rep 1996;3(4):793-803.

36. Wheelock MJ, Soler AP, Knudsen KA. Cadherin junctions in mammary tumors. J Mammary Gland Biol Neoplasia 2001;6(3):275-85.

37. Frisch SM, Ruoslahti E. Integrins and anoikis. Curr Opin Cell Biol 1997;9(5):701-6.

38. Peluso JJ, Pappalardo A, Fernandez G. E-cadherin-mediated cell contact prevents apoptosis of spontaneously immortalized granulosa cells by regulating Akt kinase activity. Biol Reprod 2001;64(4):1183-90.

39. Pece S, Gutkind JS. E-cadherin and Hakai: signalling, remodeling or destruction? Nat Cell Biol 2002;4(4):E72-4.

40. Steinhusen U, Weiske J, Badock V, Tauber R, Bommert K, Huber O. Cleavage and shedding of E-cadherin after induction of apoptosis. J Biol Chem 2001;276(7):4972-80.

41. Steinhusen U, Badock V, Bauer A, Behrens J, Wittman-Liebold B, Dorken B, et al. Apoptosis-induced cleavage of beta-catenin by caspase- 3 results in proteolytic fragments with reduced transactivation potential. J Biol Chem 2000;275(21):16345-53. 